\title{
Effect of environmental factors and bulb mass on the invasive geophyte Oxalis pes-caprae development
}

\author{
Dolors Verdaguer $^{\mathrm{a}, *}$, Anna Sala ${ }^{\mathrm{b}}$, Montserrat Vila \\ a Rrea de Fisiologia Vegetal, Departament de Ciencies Ambientals, Universitat de Girona, Campus de Montilivi s/n, 17071 Girona, Catalonia, Spain \\ b Division of Biological Sciences, The University of Montana, Missoula, MT-59812, USA \\ staciỏn Biolỏgica de Donana (EBD-CSIC), Avda/Mar̉a Luisa s/n, Pabellỏn del Perủ, 41013 Sevilla, Spain
}

Keywords:

Biomass allocation

Bulb development

Clonal growth

Light availability

Ontogeny

Planting depth

Vegetative reproduction a b s t r a c t

Oxalis pes-caprae is an invasive pseudoannual plant that reproduces exclusively via offspring bulbs in the introduced range. It is most abundant in disturbed, fertile sites such as agricultural fields, but it is also found in undisturbed shrublands and shadier forest habitats. Oxalis infestation depends on long distance bulb dispersal (mainly anthropogenic) and on the ability of bulbs to grow and reproduce successfully. We conducted a greenhouse experiment to test the effects of parent bulb size on Oxalis growth and offspring production as a function of light availability (ambient and shade), planting depth (surface vs. $9 \mathrm{~cm}$ deep), and soil volume (full pots and pots with reduced soil volume). Oxalis grew and reproduced prolifically in all treatments. However, plant development and final offspring bulb production were sensitive to environmental conditions. Shading and reduced soil volume reduced maximum plant biomass relative to control and planting depth treatments, which produced either higher number of offspring bulbs (control) or larger offspring bulbs and higher total offspring bulb biomass (planting depth). Parent bulb size and vegetative reproductive organs had little effect on plant growth and offspring production. Our results are consistent with the lower abundance of Oxalis in undisturbed soils and shadier habitats in the field but indicate that even in these marginal habitats Oxalis can reproduce prolifically and contribute to further spread.

\section{Introduction}

Rapid and prolific reproduction is an important trait in many invasive plants (Martỉnez-Ghersa and Ghersa, 2006; Sharma et al., 2005). Some species with sexual and clonal growth in their native range have shifted to almost obligate clonal reproduction in their introduced range (Barrett et al., 2008). This shift has been attributed to the reproductive advantage of asexual reproduction during the initial stages of invasion when founding populations are small (Barrett et al., 2008). However, in clonal plants long distance spread is possible only if there is a dispersal vector and if phenotypic plasticity overcomes the lack of genetic variability thereby allowing establishment in a wide range of environmental conditions (Baker, 1965; Parker et al., 2003).

Oxalis pes-caprae (Oxalidaceae, Bermuda butter-cup or soursob; hereafter Oxalis) is a pseudoannual geophyte native to southern Africa that has become invasive in many Mediterranean, temperate and sub-tropical regions of the world since the beginning of the twentieth century (Pierce, 1997). It is considered a noxious weed

\footnotetext{
* Corresponding author. Tel.: p34 972 418174; fax: p34 972418150. E-mail address: dolors.verdaguer@udg.edu (D. Verdaguer).
}

with important economic costs due to the production of oxalates which reduce crop and forage value (Marshall, 1987; Pierce, 1997; Parsons and Cuthbertson, 2001). Although in the native range Oxalis exhibits sexual and clonal reproduction via bulbs, reproduction is almost exclusively clonal in the introduced range (Galil, 1968; Ornduff, 1987; Castro et al., 2007). Offspring bulbs are deposited near parent plants, and long distance movement is mostly due to anthropogenic factors, although floods and wind may occasionally facilitate movement, and birds may act as possible dispersal vectors (Parsons and Cuthbertson, 2001). Throughout its invasive range, Oxalis is most abundant in ruderal habitats with disturbed and welldrained fertile soils (e.g. old fields, pastures, tree groves, and road margins) although it is also found in less disturbed and shaded habitats such as shrublands and forests (Gimeno et al., 2006).

Habitat characteristics and growing conditions are known to affect Oxalis performance. For instance, experimental field tests have shown that Oxalis establishment rates are higher in old fields than shrublands (Vila et al., 2008). Similarly, increased nutrient availability has a strong positive effect on Oxalis growth and offspring production, while the reverse is true with increasing inter-, and to a lower extent, intra-specific competition (Lane, 1984; Vila et al., 2006; Sala et al., 2007). Competitive effects have been partially 
attributed to the negative effects of shading on plant growth and offspring production (Galil, 1968; Lane, 1984). The depth at which bulbs reside in the soil also influences Oxalis growth and development (Galil, 1968) with delayed emergence from deeper bulbs, particularly if these are small (Lane, 1984). Larger Oxalis bulbs generally (but not always) produce larger plants and more offspring (Lane, 1984; Sala et al., 2007). Overall, these studies suggest that the lower Oxalis abundance in shrublands and forests is due in part to decreased soil fertility and shade. In addition, size-dependent propagule dispersal (e.g. if smaller bulbs are dispersed farther by wind or rain to marginal habitats) and shallower, undisturbed soils in these habitats may also limit Oxalis performance. To date, however, the extent to which Oxalis offspring production is influenced by the soil depth at which parent bulbs reside and whether this effect is size-dependent is not known. It is also not known whether responses to shade depend on parent bulb size.

The effect of parent bulb size on growth and development is likely mediated through stored reserves (Zimmerman and Whigham, 1992; Ruiters and McKenzie, 1994; Wyka, 1999; Werger and Huber, 2006; Ranwala and Miller, 2008). In non-bulbous species with vegetative reproduction, however, studies to date do not show consistent effects of propagule size on subsequent plant growth and offspring production (Verburg et al., 1996; Dushyantha and Whigham, 1997; Santamarỉa and Rodrỉguez-Gironẻs, 2002; Werger and Huber, 2006). Further, environmental stress has been shown to result in larger offspring propagules (Dong et al., 1997; Pujalon et al., 2008), likely reflecting tradeoffs between offspring number and size (Dong et al., 1997). Santamarỉa and Rodrỉguez-Gironẻs (2002) also found larger offspring propagules from mother propagules located at deeper relative to shallower soil layers. Overall these studies show that patterns of offspring production are influenced by many interacting factors and that they may be species-dependent.

In bulbous species, the effect of bulb size and growing conditions on plant growth and offspring production has received little attention. Further, available data are mostly restricted to a few ornamentals (e.g. tulips, peonies, lilies) or edible crop species (e.g. onion, garlic, shallot and leek) where research is focused on the yield of the consumed plant organ (Nojiri et al., 1992; De Hertogh and Le Nard, 1993; Ravnikar et al., 1993; Kamenetsky, 1994; Kamenetsky and Japarova, 1997; Yamazaki et al., 1998, 2000; GuenLe Saos et al., 2002). In contrast, information for wild bulbous species is very limited, particularly for invasive bulbous species with no sexual reproduction (as in Oxalis). In these species such information may provide important insight on the spread potential in different habitats.

Here we expand on previous work and report on the effects of parent bulb size on Oxalis growth and offspring production as a function of light availability (ambient and shade), depth of soil at which parent bulbs are deposited (surface vs. $9 \mathrm{~cm}$ deep), and soil volume (full pots and pots with reduced soil volume). The effects of soil volume were tested to assess the extent to which Oxalis growth and reproduction is limited in confined spaces (e.g. thin soils on rocky substrates; cracks on walls), where small, soil patches may limit the expansion of underground organs and subsequent offspring production (Galil, 1968). We also examined the ontogenic traits that underlie bulb development and their responsiveness to growing conditions. Specifically, we asked: a) Does parent bulb mass influence plant development and offspring bulb production?, if so, b) is this effect sensitive to growing conditions (light availability, planting depth and volume of soil); alternatively, c) is offspring production mainly determined by environmental effects on plant growth, regardless of parent bulb size?; d) is the development of organs leading to offspring production sensitive to growing conditions?

\section{Material and methods}

\subsection{Study species}

In Mediterranean ecosystems Oxalis bulbs remain dormant in the summer and sprout in the autumn (VilB et al., 2006). Upon sprouting, a short vertical underground shoot with lateral fine roots elongates from the parent bulb from which the rosette of leaves arise (Fig. 1). At the base of the parent bulb a fleshy contractile root starts to develop after some leaves have emerged, which later in the season serves as storage root tuber (Fig. 1). Later, the contraction of the tuber

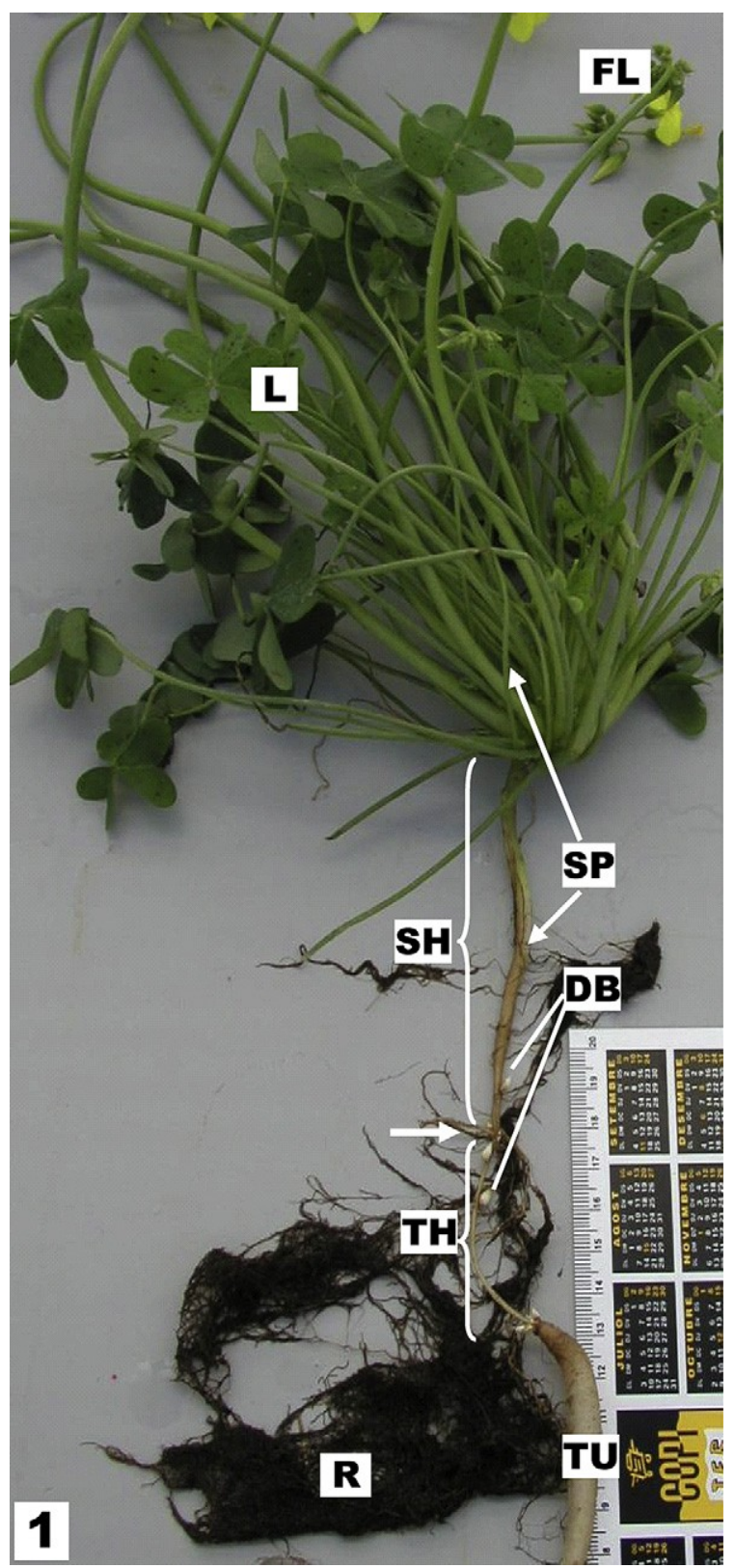

Fig. 1. Oxalis pes-caprae organs at its stage of maximum aboveground biomass. Some flowers (FL) are shown. At the base of the rosette of leaves the two parts of the underground shoot are viewed. The upper thicker and rootless part named the shoot (SH), and the thinner bearing root lower part the thread (TH). The shoot and the threat present several nodes. Along the shoot and the thread some offspring bulbs (DB) are in development. At the shoot level a sprout (SP) provides more leaves to the rosette. Below the thread, the tuber is observed. The arrow indicates the position of the parent bulb before the contraction of the tuber and the elongation of the thread. Abbreviations: DB, offspring bulb; FL, flower; L, leaves; R, roots; SH, shoot; SP, sprout; TH, thread; TU, tuber. 
elongated the 'thread' (the thin, rootless basal section of the shoot) to deeper soil horizons, which is thought to carry most new offspring bulbs (Chawdhry and Sagar, 1973; P€tz, 1994; Fig. 1). Offspring bulbs may also arise from the shoot. Mature plants develop peduncles bearing flowers (Fig. 1), although no viable seeds are produced in the invasive range. Peak vegetative growth followed by flowering occurs in winter, and plants completely senesce in spring (Vill et al., 2006). At the time of plant senescence, the tuber reserves are exhausted as offspring bulbs develop to final size. A more detailed graphical description of plant development can be found in P€tz (1994).

\subsection{Greenhouse experiment}

Total offspring bulb production and mean bulb size varies substantially among plants and populations (VilB and Gimeno, 2006). To prevent bias due to this variation, we collected bulbs in Menorca (Balearic Islands, Spain) from distinct populations and grew them in a greenhouse at the University of Barcelona (Spain) for two generations to remove potential maternal effects. At the end of the second generation, all bulbs from 20 randomly selected plants were pooled in a bag and sorted in 10 size classes (from an average of $0.08 \mathrm{~g}$ in the smallest size class to $0.8 \mathrm{~g}$ in the largest size class). Eight sets of 10 bulbs with a bulb from each size class (i. e. average $0.08 \mathrm{~g}$ in the smallest size class to $0.8 \mathrm{~g}$ in the largest size class) were selected. Two sets of bulbs were assigned to one of the following four treatments: a) bulbs planted at the pot soil surface (i.e., $1 \mathrm{~cm}$ deep) under natural greenhouse light conditions as the control treatment (C 1/4 Control); b) bulbs planted at the pot surface under natural greenhouse light conditions but with soil volume reduced to half (V 1/4 Reduced Volume); c) bulbs planted at the pot surface under low PAR (LL 1/4 Low Light) and d) bulbs planted at $9 \mathrm{~cm}$ depth under natural greenhouse light conditions (D $1 / 4$ Depth). Although parent bulbs are able to grow and produce offspring at substantially deeper soil layers (Galil, 1968), planting depth was limited to $9 \mathrm{~cm}$ for logistical reasons. One of the two sets per treatment was assigned to a first harvest at the time of maximum aboveground biomass and flowering, and the other to the final harvest when plants had completely senesced and offspring bulbs were mature.

In total 80 bulbs were planted. Before planting, each bulb was weighted to verify that mean bulb weight was the same for each set (average \pm SE, $0.36 \mathrm{~g} \pm 0.07$ ). Bulbs were sown into $2 \mathrm{~L}$ plastic pots (11.5 cm in diameter $\times 21 \mathrm{~cm}$ in depth) filled with silica sand on October 22, 2003. Reduction of soil volume in the V treatment was accomplished by placing a piece of cloth impermeable to roots but not to water at $7 \mathrm{~cm}$ below the soil surface with the cloth surrounding the pot walls to the top of the pot to prevent root penetration to the lower soil. Light reduction was implemented at the time of emergence, when LL pots were separated from the rest and placed under a neutral mesh that reduced the PAR ca. $70 \%$ for the remaining of the experiment (average PAR inside the greenhouse on clear days was $\left.800 \mathrm{mmol} \mathrm{m}^{-2} \mathrm{~s}^{-1}\right)$.

All pots were initially watered to field capacity and, with the exception of pots placed under shade, treatments were completely randomized. During the first three weeks, pots were subjected to a 1 min surface misting three times a day to maintain surface soil moisture. After two weeks (November 6th) 78\% of bulbs had emerged; and after 3 weeks emergence was $100 \%$. Pots were watered periodically every 6 (initially) to 3 days with $200 \mathrm{ml}$ (about field capacity) of $1 / 2$ strength Hoagland solution. All pots were rotated every two weeks to avoid any position effect.

On March 2004, five months after initial sowing, when plants had reached maximum aboveground development and were flowering, plants from one set from each treatment were harvested and morphological measurements were taken. Each plant was divided into six fractions: flowers, leaves, tuber, fine roots, shoot and thread (Fig. 1). We refer to the shoot as the robust stem between the rosette of leaves and the parent bulb, and to the thread as the rootless, thin stem between the shoot and the tuber (Galil, 1968). Shoot and thread comprise the vegetative reproduction organ (hereafter VRO). Therefore, belowground biomass is the sum of roots, tuber and VRO. The following measurements were taken in the VRO: length and number of nodes of the shoot and thread, and the number of offspring bulbs originated from the shoot and thread nodes. All plant parts were washed with tap water to remove all sand particles, and dried in a ventilated oven at $65{ }^{\circ} \mathrm{C}$ to constant weight.

On July 2004 when plants were nine months old and the aboveground biomass had completely senesced (senescent state), the remaining pots were harvested for bulb production. Two categories of bulbs were distinguished: hypogeous bulbs, originated from the shoot and thread and epigeous bulbs, which are leaf axillary buds originated from meristematic tissues at the base of the rosette of leaves.

\subsection{Statistical analysis}

One-way analysis of covariance (ANCOVA) was performed to determine the effect of treatment (fixed factor) and the parent bulb mass (covariate) on the following Oxalis parameters: aboveground biomass (leaves and flowers), belowground biomass (root, tuber, and VRO), biomass allocation leaf weight ratio (LWR, leaf dry weight/total plant dry weight), root weight ratio (RWR, root dry weight/total plant dry weight) and VRO weight ratio (VROWR, VRO dry weight/ total plant dry weight), length and number of nodes in the shoot and thread, number of offspring bulbs at the first harvest; number and biomass of offspring bulbs, as well as average bulb size (biomass) at the end of the experiment. Pair-wise differences among treatments were compared by Bonferroni post-hoc test $(p<0.05)$. When the treatment $x$ covariate interaction was statistically significant, ANCOVAs were performed between the dependent variable and the parent bulb mass for each treatment. One-way analysis of covariance was also performed to determine the effect of shoot length on node development. Assumptions of normality and homoscedasticity were tested by the KolmogoroveSmirnov test and Levene's test, respectively. In order to normalise error variances and heteroscedasticity, length of shoot and thread and number of nodes and offspring bulbs were square-root transformed, biomass was log-transformed and ratios were arcsinsquare root-transformed prior to analysis. Statistical significance was set at $\mathrm{p}<0.05$ unless otherwise specified. All statistical analyses and figures were conducted using the software SPSS for Windows (Versions 13.0, SPSS Inc., Chicago IL., USA).

\section{Results}

\subsection{Biomass of non-reproductive components}

Parent bulb mass had a weak significant positive effect on total plant biomass at the first harvest $\left(F_{1,35}\right.$ 1/4 5.12, p 1/4 0.032, $\left.\mathrm{r}^{2} 1 / 40.822\right)$, although this effect was only due to a slight, but significant, positive effect on root biomass $\left(F_{1,40} 1 / 44.23, p 1 / 40.048, r^{2} 1 / 40.498\right)$. Further, there was a nearly significant parent bulb mass $x$ treatment interaction $\left(F_{1,35} 1 / 42.924, \mathrm{p}^{1 / 4}\right.$ 0.052) and analyses by treatment indicated that parent bulb mass influenced total plant biomass only in the low light treatment $\left(F_{1,9} 1 / 417.653, p^{1 / 4} 0.004, r^{2} 1 / 40.722\right)$. Neither leaf nor tuber biomass were affected by parent bulb mass. While LWR was significantly and positively related to parent bulb mass $\left(F_{1,35} 1 / 47.09\right.$, p 1/4 0.012; Table 1), RWR was not $\left(F_{1,35} 1 / 40.39\right.$, p 1/4 0.534; Table 1$)$. Parent bulb mass was positively related to flower mass, but only in the low light treatment where larger parent bulbs resulted in higher the flower mass $\left(F_{1,10} 1 / 4\right.$ 29.11, p 1/4 0.001, $\mathrm{r}^{2}$ 1/4 0.784; parent bulb mass $\times$ treatment interaction: $F_{1,40} 1 / 4$ 3.82, $\mathrm{p} 1 / 4$ 0.019; Fig. 2).

Total plant biomass was similar in control plants (grown under natural light and high soil volume) relative to plants from bulbs 
Table 1

Biomass allocation and vegetative reproduction organ traits for Oxalis from the first harvest at the time of maximum plant growth. Values are mean ( \pm standard error). Values of $\mathrm{n}$ (sample size), $\mathrm{F}$ for the fixed factor (treatment) and the significance $\mathrm{p}$ for the factor and the covariate (parent bulb mass) derived from the analysis of ANCOVA are included. Within a variable the A letter capital or lower case indicate significant differences. Abbreviations: cov, covariate; ns, not statistically significant; LWR, leaf weight ratio; RWR, root weight ratio; VRO, vegetative reproduction organ; VROWR, vegetative reproduction organ weight ratio.

\begin{tabular}{|c|c|c|c|c|c|c|c|c|c|c|c|c|}
\hline & \multicolumn{12}{|c|}{ Biomass allocation and vegetative reproduction organ traits (VRO) } \\
\hline & Surface & & Depth & & Soil volume & & Low PAR & & $\mathrm{n}$ & $\mathrm{F}$ & $\mathrm{p}$ (factor) & $\mathrm{p}(\operatorname{cov})$ \\
\hline LWR (g/g) & $0.430 \pm 0.013$ & A & $0.465 \pm 0.016$ & A & $0.426 \pm 0.014$ & A & $0.607 \pm 0.030$ & a & 35 & 20.981 & 0.000 & 0.012 \\
\hline RWR (g/g) & $0.063 \pm 0.007$ & A & $0.064 \pm 0.005$ & A & $0.106 \pm 0.010$ & a & $0.062 \pm 0.006$ & A & 35 & 8.260 & 0.000 & ns \\
\hline VRO dw (g) & $0.098 \pm 0.010$ & A & $0.203 \pm 0.015$ & a & $0.098 \pm 0.033$ & A & $0.087 \pm 0.024$ & A & 36 & 6262 & 0.002 & ns \\
\hline VROWR (g/g) & $0.017 \pm 0.002$ & A & $0.034 \pm 0.002$ & A & $0.029 \pm 0.011$ & A & $0.029 \pm 0.008$ & A & 35 & 2100 & ns & ns \\
\hline \multicolumn{13}{|l|}{ Shoot } \\
\hline Length $(\mathrm{cm})$ & $2.720 \pm 0.671$ & A & $10.240 \pm 0.459$ & a & $2.790 \pm 0.542$ & A & $3.160 \pm 0.579$ & A & 40 & 43,995 & 0.000 & 0.002 \\
\hline$n^{0}$ nodes & $3.100 \pm 0.433$ & A & $7.400 \pm 0.400$ & a & $2.400 \pm 0.371$ & A & $3.400 \pm 0.427$ & A & 40 & 26,557 & 0.000 & ns \\
\hline dw (g) & $0.056 \pm 0.008$ & A & $0.147 \pm 0.012$ & a & $0.043 \pm 0.006$ & A & $0.061 \pm 0.024$ & A & 36 & 11,141 & 0.000 & ns \\
\hline \multicolumn{13}{|l|}{ Thread } \\
\hline Length (cm) & $1.874 \pm 0.273$ & A & $5.920 \pm 0.172$ & a & $2.280 \pm 0.489$ & A & $1.990 \pm 0.219$ & A & 40 & 36,893 & 0.000 & ns \\
\hline $\mathrm{n}^{0}$ nodes & $3.500 \pm 0.167$ & A & $3.800 \pm 0.200$ & A & $3.300 \pm 0.153$ & A & $3.500 \pm 0.167$ & A & 40 & 1449 & ns & ns \\
\hline dw (g) & $0.043 \pm 0.004$ & A & $0.056 \pm 0.007$ & A & $0.055 \pm 0.029$ & A & $0.026 \pm 0.005$ & A & 36 & 0.858 & ns & ns \\
\hline \multicolumn{13}{|c|}{ Offspring bulbs $\left(\mathrm{n}^{0}\right)$} \\
\hline Shoot & $0.200 \pm 0.133$ & A & $4.800 \pm 0.646$ & a & $0.400 \pm 0.221$ & A & $0.000 \pm 0.000$ & A & 40 & 32,486 & 0.000 & ns \\
\hline Thread & $13.900 \pm 1.410$ & A & $11.200 \pm 0.593$ & A & $12.100 \pm 0.912$ & A & $11.900 \pm 0.526$ & A & 40 & 1400 & ns & ns \\
\hline
\end{tabular}

planted at depth. However, it was about 1.5 times larger relative to plants from bulbs subjected to reduced soil volume or to low light (Fig. 3A). Total belowground biomass was highest in control plants and lowest in shaded plants, with intermediate values in the soil depth and reduced soil volume treatments (Fig. 3B). Tuber mass was also largest in the control treatment with reductions from 45 to $65 \%$ in the remaining treatments (Fig. 3B), which were not statistically different among each other. Root biomass was similar among the control, soil depth and low soil volume treatments, with ca. $60 \%$ higher values relative to the low light (Fig. 3B). Shaded plants allocated a higher proportion of biomass to leaves whereas low volume soil plants allocated a higher proportion to roots (Table 1).

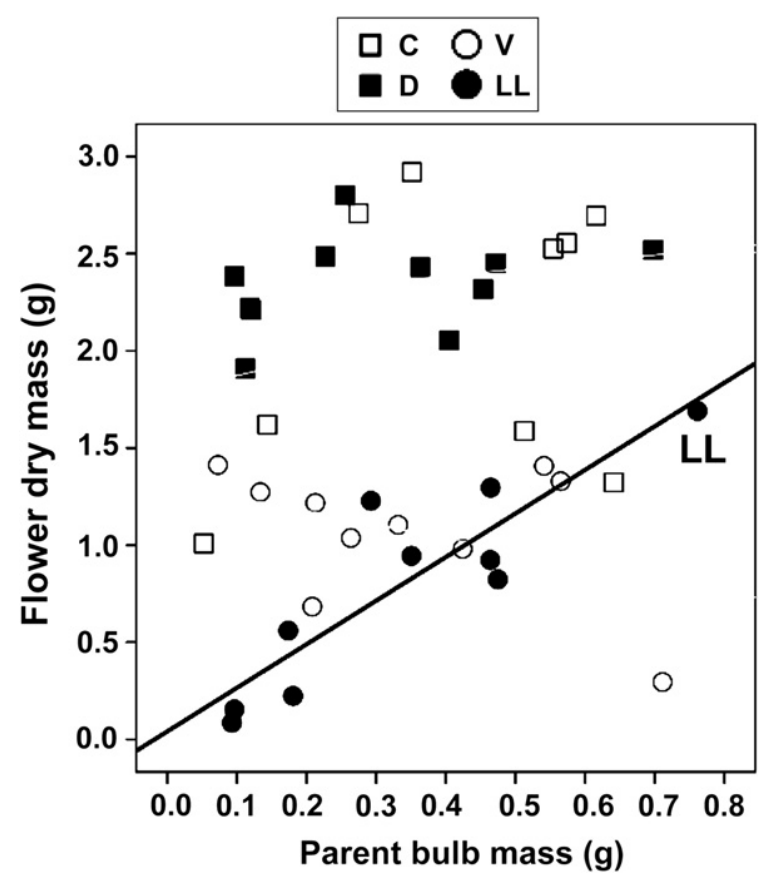

Fig. 2. Relationship between parent bulb mass and flower mass at the first harvest (maximum plant biomass) in the different treatments. A significant linear regression was only found for the low light treatment. Abbreviations: C, control; D, depth; V, low volume soil; LL, low light treatments.

\subsection{Vegetative reproductive organ and bulb development}

Parent bulb biomass did not affect the development of the vegetative reproduction organ (VRO), with the exception of the shoot length (Table 1): larger parent bulbs produced longer shoots $\left(\mathrm{F}_{1,40} 1 / 4\right.$ 10.428, $\mathrm{p} 1 \frac{1}{4}$ 0.003) (Fig. 4A) consisting of more nodes (Fig. 4B). While the proportion of biomass allocation to the VRO was similar among all treatments (Table 1), growing conditions influenced its total biomass: bulbs planted at depth produced a VRO approximately two-fold heavier than that of plants from the other treatments (Table 1). This increase was largely due to a ca. five-fold longer and two-fold heavier shoot, bearing the highest number of nodes (ca. 8) (Table 1; Fig. 4A). Plants from bulbs planted at depth had a significantly longer thread, although no differences in the thread dry mass were detected. The number of thread nodes was 3 or 4 in all bulbs (Table 1).

Offspring bulbs developed from axillary buds at the shoot and thread nodes. Bulbs in different developmental stages were observed at a single node indicating that bulb development was not synchronous. The initiation of bulb development followed an acropetal ontogenic sequence: it started first from nodes of the thread (below the shoot, and closer to the tuber) and then from nodes of the shoot. Therefore, at the maximum biomass stage (i.e., the first harvest) there were few activated axillary buds at the shoot in some treatments (Table 1). For instance, no initiated offspring bulbs were observed in the shoot in the shading treatment (Table 1). In contrast, bulbs from the soil depth treatment had the highest number of initiated offspring bulbs from the shoot (Table 1). The number of offspring bulbs in the thread was similar among treatments (Table 1).

\subsection{Bulb production}

Overall, number of offspring bulbs varied over a 5 -fold range (18e99), individual bulb mass over a 15-fold range (0.045e0.751 g) and total offspring biomass over a 25-fold range (1.16e30.04 g). Parent bulb mass did not influence the total number and biomass of offspring bulbs and the size of individual bulbs. However, treatments greatly influenced bulb production and size (Fig. 5): while control plants produced about 1.5 times more bulbs than plants from any other treatment (Fig. 5A), total offspring bulb biomass and size (mass) of individual bulbs was much higher in plants from bulbs planted at 

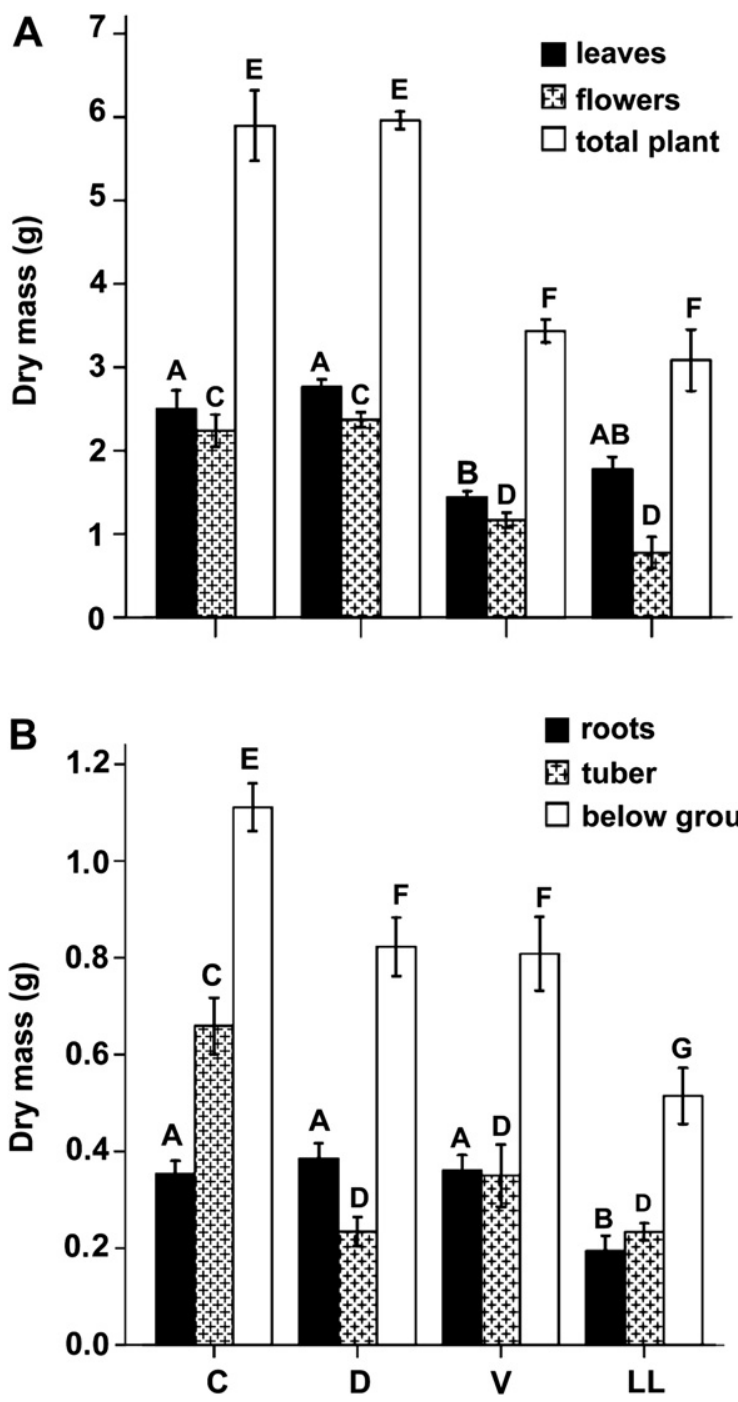

Fig. 3. Biomass of Oxalis organs at the first harvest (maximum plant biomass) as a function of treatment. Values are means ( \pm standard error) for (A) leaves (shaded bars), flowers (hatched bars) and total plant (open bars); (B) roots (shaded bars), tuber (hatched bars) and belowground (open bars). Within a given biomass fraction, different letters denote significant differences among treatments $(\mathrm{p}<0.05)$. Abbreviations: $\mathrm{C}$ : control; $\mathrm{D}$, depth; V, reduced soil volume and LL, reduced low light treatments.

depth (Fig. 5B and C). Differences in bulb number and biomass were mainly accounted for by hypogeous bulbs, which were much larger $(12 x)$ than epigeous bulbs. Although epigeous bulbs contributed to a very small fraction of total bulb biomass, they represented about $40 \%$ of the total number produced. Number and total biomass of epigeous bulbs were similar for all treatments (Fig. 5A and B).

\section{Discussion}

Consistent with its invasive capacity, Oxalis was able to grow and to reproduce prolifically in all treatments. Total offspring production per plant exceeded in all cases 35 bulbs, of which over 20 were hypogeous, larger bulbs and the rest epigeous, smaller bulbs. In spite of this, development and final offspring bulb production were highly sensitive to environmental conditions: shading and reduced soil volume produced much smaller plants than control and soil depth treatment indicating a negative effect of limiting light and soil resources. Differences in maximum plant biomass translated to either a higher number of offspring bulbs
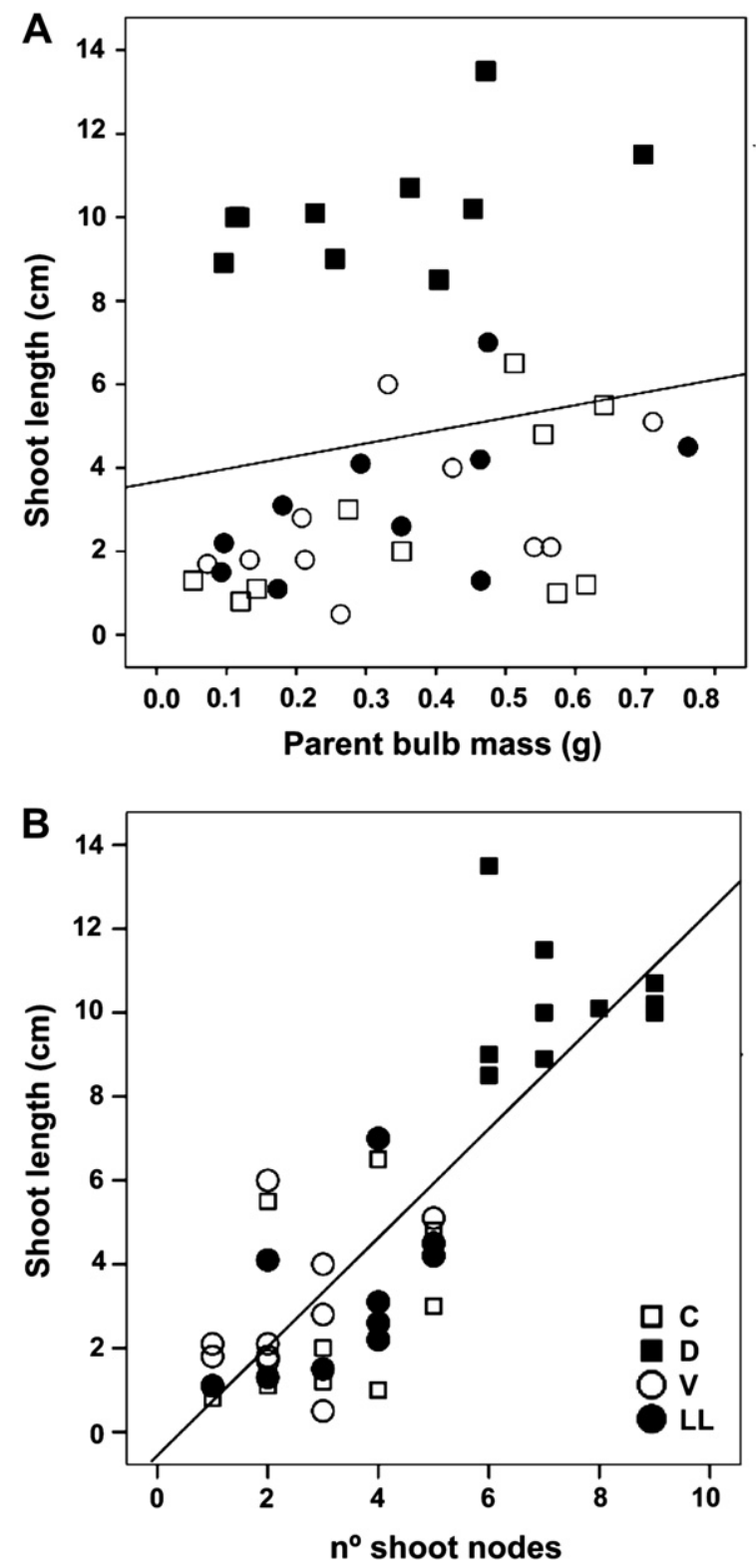

Fig. 4. Relationship between (A), parent bulb mass and shoot length, and (B) shoot length and number of shoot nodes in Oxalis grown under different treatments at the first harvest (maximum plant biomass). Only statistically significant linear regressions are shown. Abbreviations: C: control; D, depth; V, reduced soil volume and LL, reduced low light treatments.

(control treatment) or a higher total bulb biomass (planting depth). In contrast, parent bulb mass and VRO traits did not influence the number or the total biomass of offspring bulbs. Our results show that in spite of environmental constraints Oxalis reproductive capacity remains very high suggesting that even marginal habitats might be sources of propagules and contribute to further spread.

\subsection{Effect of treatments and parent bulb mass on Oxalis growth}

Overall we found that parent bulb size had small effects on plant biomass and no effect on final offspring bulb production. Under limiting resource availability Oxalis parent bulbs may initially provide resources to developing plants (Sala et al., 2007). However, and consistent with Chawdhry and Sagar (1973) vegetative growth apparently became independent of parent bulb once plants produced 

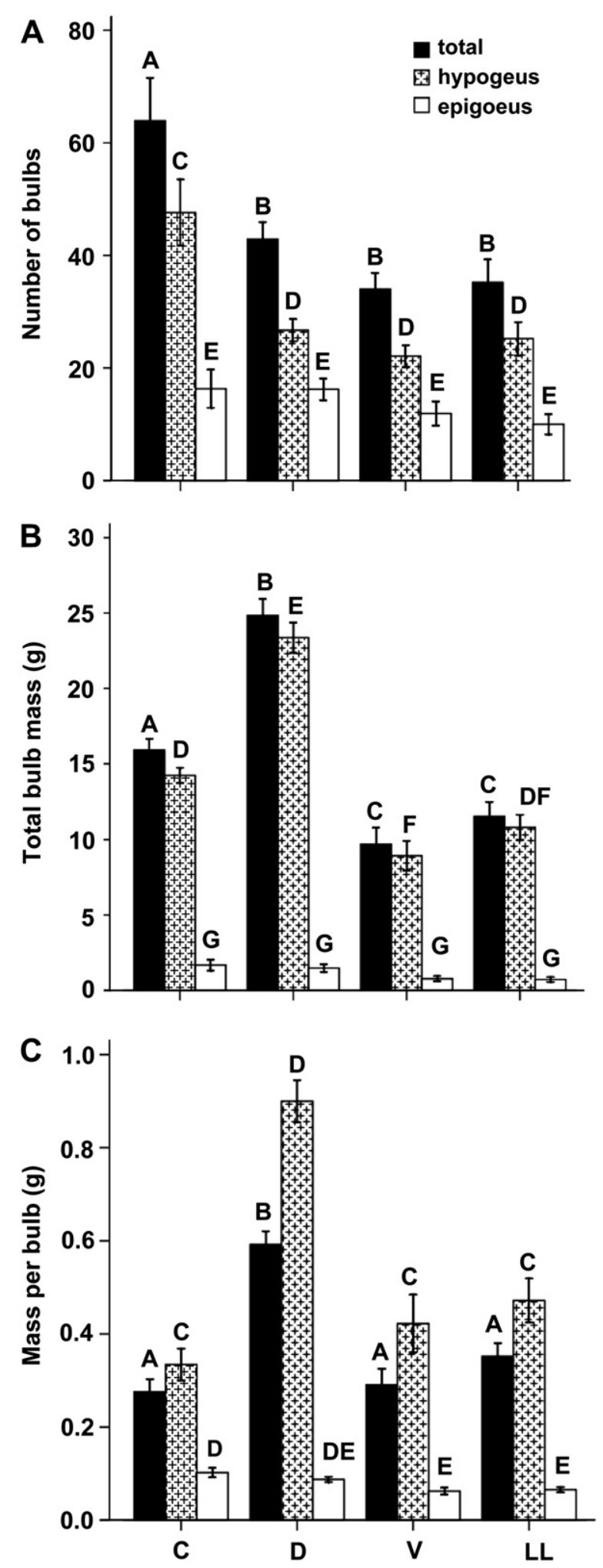

Fig. 5. Oxalis offspring production at the final harvest (when all above ground organs had senesced) as a function of treatment. (A) Total number of bulbs (shaded bars), number of hypogeous bulbs (hatched bars) and number of epigeous bulbs (open bars); (B) total biomass of all bulbs (shaded bars), of hypogeous bulbs (hatched bars) and of epigeous bulbs (open bars); (C) mass per bulb of all bulbs combined (shaded bars), hypogeous bulbs (hatched bars) and epigeous bulbs (open bars). Within a given fraction, different letters denote significant differences among treatments $(p<0.05)$. Abbreviations: C: control; D, depth; V, reduced soil volume and LL, reduced low light treatments. leaves and started exporting carbohydrates to underground organs. Similar results in tuberous species were reported by Santamarỉa and Rodrỉguez-Gironẻs (2002) and Werger and Huber (2006).

Increases in biomass allocation towards organs that capture the most limiting resources (in this study, roots and leaves; Bloom et al., 1985) and differences in nutrients or light availability are consistent with the lower performance of plants from the low soil volume and low light treatments. Although plants under low soil volume allocated more biomass to roots, it is likely that the lower bulb production (number and biomass) was due to insufficient total soil resource pools with which to supply the leaves. Similarly, shaded plants allocated more biomass to leaves, but light-limited carbon assimilation apparently limited carbon availability for root development and subsequent bulb production.

It is worth noting the significant flower biomass produced in all treatments. Such investment in flowers may be mal-adaptive in invasive Oxalis where sexual reproduction has been lost and where asexual reproduction is strongly dependent on resources. The relationship between parent bulb size and flower biomass in the shade treatment suggests a genetically controlled investment in flowers. Such genetic constraint combined with reduced carbon assimilation in the shade may increase the dependency of flower production on bulb stored resources and parent bulb size. Consistently, vegetative propagules have been shown to influence flower development in other species with vegetative reproduction (Verburg and Grava, 1998; Orthen and Wehrmeyer, 2004).

\subsection{Effect of treatment in bulb production}

Although Oxalis bulb initiation starts very early after the contraction of the tuberous root (Chawdhry and Sagar, 1973), most buds initiate and develop to final size after plants reach maximum aboveground growth and start to senesce. This explains why the number of developing buds at the first harvest (stage of maximum plant biomass) was not related to final offspring bulb number. For instance, the number of bulbs in the control treatment increased by ca. $70 \%$ from the first to the final harvest.

Plants from bulbs planted at depth produced higher total offspring bulb biomass and heavier bulbs. This was related to substantially longer and heavier shoots but not to heavier tubers, suggesting that the shoot may partially substitute for the role of the tuber as a supply of reserves for bulb enlargement (see Galil, 1968). The mechanisms underlying increases in bulb size with soil depth could involve phytochrome responses (Sato-Nara et al., 2004) as demonstrated in onion (Yamazaki et al., 1998).

Higher bulb number in control plants but heavier bulbs in the planting depth treatment are consistent with propagule size-number tradeoffs models suggesting that greater number of offspring are advantageous in non-stressful environments, while larger offspring size at the cost of reduced number of offspring are advantageous in stressful environments (Smith and Fretwell, 1974; Sadras, 2007). We found that emergence was not influenced by parent bulb size, likely because even the smallest bulbs (average of $0.08 \mathrm{~g}$ ) provided sufficient resources to elongate $9 \mathrm{~cm}$ up to the soil surface. In the field, however, larger bulbs may be required to supply reserves to emerge from greater soil depths (Lane, 1984).

\subsection{Ontogeny of bulb production}

The presence of contractile roots in most species has been related to the benefits of pulling down geophilic organs into soil layers where environmental conditions are more stable (Jaffe and Leopold, 2007). In Oxalis, root contraction is critical to elongate the thread and to allow offspring bulb distribution along the soil profile (Galil, 1968; P€tz, 1994). Therefore, plastic responses in thread 
development as a function of environment may influence offspring production and distribution along the soil profile. In contrast, we found that the number of nodes in the thread remained constant regardless of treatment. Instead, the number of nodes in the shoot increased in bulbs planted $9 \mathrm{~cm}$ below the soil surface, but this did not result in more offspring bulbs. Overall, developmental differences of the vegetative reproduction organ (VRO) had no effect on Oxalis growth and development and final offspring production. For instance, all variables relating to the VRO in the reduced soil volume and reduced light treatments were similar to those of the control treatment, which produced larger plants and more bulbs.

\subsection{Implications for Oxalis invasion}

Consistent with greater Oxalis abundance in open, disturbed and fertile field sites (Gimeno et al., 2006), we found that reduced light or soil resources limited Oxalis growth and offspring production. Importantly, however, Oxalis reproduced prolifically in all treatments with an average of over 30 bulbs per plant, a value similar to that reported by Vill and Gimeno (2006) and Vill et al. (2006) from similar Menorca populations grown under favorable conditions. If similar patterns persist in the field, even marginal habitats may significantly contribute to further spread. Our results also suggest that ploughing may increase plant size and bulb production, and those plastic responses such as the production of larger offspring at greater sol depths may facilitate Oxalis spread. The little influence of parent bulb size on final bulb production (see also Sala et al., 2007) may explain the low success of efforts to eradicate Oxalis (VilB and Gimeno, 2007). This is because small bulbs are difficult to locate and remove, but they can grow and reproduce prolifically. The ability of Oxalis to produce both hypogeous and epigeous bulbs is likely significant as well. Although epigeous bulbs are very small and comprise a very small fraction of total offspring biomass, their average size in the control and soil depth treatment was very close to or at the minimum parent bulb size we tested in our experiment. Evidently, even these small bulbs have the potential to grow and reproduce well, particularly under favorable conditions. Therefore, their production may be a strategy to enhance spread at a very small cost.

\section{Acknowledgements}

We thank J. Matas from the UB and I. Bartomeus from CREAF for their assistance in the greenhouse and in the laboratory and comments from three anonymous referees. Support to AS was provided by the Government of Catalonia via a Visiting Research Professorship awarded to MV. Partial research support was provided and by the Integrated European Project ALARM e Assessing Large Scale Risks to Biodiversity with tested Methods (ALARM: http:// www.alarmproject.net), contract 506675 to MV and by the DGICYT (AGL2002-02136 AGR-FOR) to DV. Thanks to the Institute of Environmental Science and Technology (ICTA) of the Autonomous University of Barcelona (UAB) for their hospitality and stimulation during AS's sabbatical.

\section{References}

Baker, H.G., 1965. Characteristics and modes of origins of weeds. In: Baker, H.G., Stebbins, G.L. (Eds.), The Genetics of Colonizing Species. Academic Press, New York, pp. 147e172.

Barrett, S.-C.H., Colautti, R.I., Eckert, C.G., 2008. Plant reproductive systems and evolution during biological invasion. Mol. Ecol. 17, 373 e383.

Bloom, A.J., Chapin, F.S., Mooney, H.A., 1985. Resource limitation in plants e an economic analogy. Ann. Rev. Ecol. Syst. 16, 363e392.

Castro, S., Loureiro, J., Santos, C., Ater, M., Ayensa, G., Navarro, L., 2007. Distribution of flower morphs, ploidy level and sexual reproduction of the invasive weed Oxalis pes-caprae in the western area of the Mediterranean region. Ann. Bot. 99, 507 e517.
Chawdhry, M.A., Sagar, G.R., 1973. An autoradiographic study of the distribution of ${ }^{14} \mathrm{C}$ labelled assimilates at different stages of development of Oxalis latifolia H.B.K. and O. pes caprae L. Weed Res. 13, 430 e437.

De Hertogh, A., Le Nard, M., 1993. The Physiology of Flower Bulbs. Elsevier, The Netherlands, pp. 811

Dong, M., During, H.J., Werger, M.J.A., 1997. Clonal plasticity in response to nutrient availability in the pseudoannual herb, Trientalis europaea L. Plant Ecol. 131, $233 e 239$.

Dushyantha, K.W., Whigham, D.F., 1997. Costs of producing clonal offspring and the effects of plant size on populations dynamics of the woodland herb Uvularia perfoliata (Liliaceae). J. Ecol. 85, 907e919.

Galil, J., 1968. Vegetative dispersal in Oxalis cernua. Am. J. Bot. 55, 68e73.

Gimeno, I., VilR, M., Hulme, P.E., 2006. Are islands more susceptible to plant invasion than continents? A test using Oxalis pes-caprae in the western Mediterranean. J. Biogeogr. 33, 1559e1565.

Guen-Le Saos, F.L.E., Hourmant, A., Esnault, F., Chauvin, J.E., 2002. In vitro bulb development in shallot (Allium cepa L. Aggregatum Group): effects of antigibberellins, sucrose and light. Ann. Bot. 89, 419e425.

Jaffe, M.J., Leopold, A.C., 2007. Light activation of contractile roots of Easter Lily. J. Amer. Soc. Hortic. Sci. 132, 575e648.

Kamenetsky, R., 1994. Life cycle, flower initiation, and propagation of the desert geophyte Allium rothii. Int. J. Plant Sci. 1554, 597e605.

Kamenetsky, R., Japarova, N., 1997. Relationship between annual cycle and floral development of three Allium species from subgenus Melanocrommyum. J. Arid Environ. 35, 473e485.

Lane, D., 1984. Factors affecting the development of populations of Oxalis pes-caprae L. Weed Res. 24, 219 e225.

Marshall, G., 1987. A review of the biology and control of selected weed species in the genus Oxalis: O. stricta L., O. latifolia H.B.K. and O. pes-caprae L. Crop Prot. 6, 355e364. Martỉnez-Ghersa, M.A., Ghersa, C.M., 2006. The relationship of propagule pressure to invasion potential in plants. Euphytica 148, 87e96.

Nojiri, H., Yamane, H., Seto, H., Yamaguch, I., Murofushi, N., Yoshihara, T., Shibaoka, H., 1992. Qualitative and quantitative analysis of endogenous jasmonic acid in bulbing and non-bulbing onion plants. Plant Cell Physiol. 33, $1225 \mathrm{e} 1231$.

Ornduff, R., 1987. Reproductive systems and chromosome races of Oxalis pes-caprae L. and their bearing on the genesis of a noxious weed. Ann. Mo. Bot. Gard. 74, 79e84.

Orthen, B., Wehrmeyer, A., 2004. Seasonal dynamics of non-structural carbohydrates in bulbs and shoots of the geophyte Galanthus nivalis. Physiol. Plant. 120, $529 e 536$.

Parker, I.M., Rodriguez, J., Loik, M.E., 2003. An evolutionary approach to understanding the biology of invasions: local adaptation and general-purpose genotypes in the weed Verbascum thapsus. Conserv. Biol. 17, 59 e72.

Parsons, W.T., Cuthbertson, E.G., 2001. Soursob. In: Parson, W.T., Cuthbertson, E.G. (Eds.), Noxious Weeds of Australia. Csiro Publishing, Australia, pp. 529e534.

Pierce, J.R., 1997. The biology of Australian weeds: 31. Oxalis pes-caprae (Oxalidaceae). Plant Syst. Evol. 191, 110e119.

Pujalon, S., Piola, F., Bornette, G., 2008. Abiotic stresses increase plant regeneration ability. Evol. Ecol. 22, 493 e506.

P€tz, N., 1994. Vegetative spreading of Oxalis pes-caprae (Oxalidaceae). Plant Syst. Evol. 191, 57e67.

Ranwala, A.P., Miller, W.B., 2008. Analysis of nonstructural carbohydrates in storage organs of 30 ornamental geophytes by high-performance anion-exchange chromatography with pulsed amperometric detection. New Phytol. 180, 421e433.

Ravnikar, M., Zel, J., Plaper, I., Spacapan, A., 1993. Jasmonic acid stimulates shoot and bulb formation of garlic in vitro. J. Plant Growth Regul. 12, 73e77.

Ruiters, C., McKenzie, B., 1994. Seasonal allocation and efficiency patterns of biomass and resources in the perennial geophyte Sparaxis grandiflora subspecies fimbriata (Iridaceae) in lowland coastal fynbos, South Africa. Ann. Bot. 74, 633 e646.

Sadras, V., 2007. Evolutionary aspects of the trade-off between seed size and number in crops. Field Crops Res. 100, $125 \mathrm{e} 138$.

Sala, A., Verdaguer, D., VilR, M., 2007. Sensitivity of the invasive geophyte Oxalis pescaprae to nutrient availability and competition. Ann. Bot. 99, 637e645.

Santamarỉa, L., Rodrỉguez-Gironẻs, M.A., 2002. Hiding from swans: optimal burial depth of sago pondweed tubers foraged by Bewick's swans. J. Ecol. 90, 303e315.

Sato-Nara, K., Nagasaka, A., Yamashita, H., Ishida, J., Endu, A., Seki, M., Shinozaki, K., Suzuki, H., 2004. Identification of genes regulated by dark adaptation and farred light illumination in roots of Arabidopsis thaliana. Plant Cell Environ. 27, 1387 e1394.

Sharma, G.P., Raghubanshi, A.S., Singh, J.S., 2005. Lantana invasion: an overview. Weed Biol. Mange. 5, 157e165.

Smith, C.C., Fretwell, S.D., 1974. Genetic Improvement of Field Crops. Marcel Dekker Inc., New York, 470 pp.

Verburg, R.W., Kwant, R., Werger, M.J.A., 1996. The effect of plant size on vegetative reproduction in a pseudo-annual. Vegetatio 125, 185 e192.

Verburg, R.W., Grava, D., 1998. Differences in allocation patterns in clonal and sexual offspring in a woodland pseudo-annual. Oecologia 115, 472e477.

VilR, M., Gimeno, I., 2006. Potential for higher invasiveness of the alien Oxalispescaprae on island than on mainland. Plant Ecol. 183, 47e53.

Vila, M., Bartomeus, I., Gimeno, I., Traveset, A., Moragues, E., 2006. Demography of the invasive geophyte Oxalis pes-caprae across a Mediterranean island. Ann. Bot. 97, 1055e1062.

VilB, M., Gimeno, I., 2007. Effect of agricultural practices on Mediterranean grasslands invaded by Oxalis pes-caprae. Plant Prot. Q. 22, 62e66. 
VilB, M., Siamantziouras, A.S.D., Brundu, G., Camarda, I., Lambdon, P., Mẻdail, F., Moragues, E., Suehs, D., Traveset, A., Troumbis, A.Y., Hulme, P.E., 2008. Widespread resistance of Mediterranean island ecosystems to the establishment of three alien species. Divers. Distrib. 14, 839e851.

Werger, M.J.A., Huber, H., 2006. Tuber size variation and organ preformation constrain growth responses of a spring geophyte. Oecologia 147, 396e405.

Wyka, T., 1999. Carbohydrate storage and use in an alpine population of the perennial herb, Oxytropis sericea. Oecologia 120, 198e208.
Yamazaki, H., Oi, R., Nishijima, T., Miura, H., 1998. Inhibition of bulb development in Allium wakegi Araki under a high red/far red photon ratio. J. Jpn. Soc. Hortic. Sci. 67, 337 e340.

Yamazaki, H., Yamato, Y., Hamano, M., Miura, H., 2000. A far-red intercepting film prevents bulb formation in Allium wakegi Araki cultivated in summer. Acta Hortic. 514, 133 e138.

Zimmerman, J.K., Whigham, D.F., 1992. Ecological functions of carbohydrates stored in corms of Tipularia discolor (Orchidaceae). Funct. Ecol. 6, 575e581. 